\title{
How is public transit in the megacity peripheral relocatees' area in China? Captive transit rider and dynamic modal accessibility gap analytics in a peripheral large-scale residential area in Shanghai, China
}

\author{
Jinping Guan \\ Massachusetts Institute of Technology \\ jinpingg@mit.edu; melon_ping@163.com \\ Shuang Zhang \\ Tsinghua University
}

\author{
Kai Zhang \\ Tsinghua University \\ Yizhou Chen \\ Shenzhen Rongheng Industry Group Co.
}

\begin{abstract}
In the process of Chinese megacity suburbanization, centralcity substandard housing is demolished. The government relocates residents to megacity peripheral relocatees' areas. So far, few studies have focused on captive transit riders and analyzed the dynamic points of interest (POI) accessibility by public transit compared to the private mode in these areas. To fill this gap, this study conducts a survey in Jinhexincheng, one of these areas in Shanghai, China; analyzes captive-transit riders with multiple models; and computes the dynamic modal accessibility gap (DMAG) of public transit and private travel mode using multi-source heterogeneous data. Results show that $71.77 \%$ of transit-rider samples acknowledge they "have no other choice and have to travel by transit." These captive transit riders are more often older, female, non-working, without a driving license, and with more complaints toward public transport. Subjective transit evaluation's ordinal regression models show that waiting time, speed, operating hours, and number of lines/stops contribute to the low transit subjective evaluation. These things should be given a high priority in transit improvement. As for the captive transit riders, transit's transfer and bicycle availability should be improved. Using big data analytics, a more fine-grained scale is brought in by computing a DMAG index. It shows a person mostly has a better POI accessibility by private mode for the 30-minute, real-travel-covered area for 24 hours of the average day. For the 60-minute, real-travel-covered area, public transit mostly has a better POI accessibility. This study supports transit planning and decision-making for megacity peripheral relocatees' areas using multisource heterogeneous data analytics.
\end{abstract}

Keywords: Public transit, captive transit rider, subjective transit evaluation, dynamic modal accessibility gap, megacity peripheral relocatees' area, China

\section{Article history:}

Received: December 17, 2018

Received in revised form:

October 8, 2019

Accepted: November 7, 2019

Available online: January 29,

2020

Copyright 2020 Jinping Guan, Kai Zhang, Shuang Zhang, \& Yizhou Chen http://dx.doi.org/10.5198/jtlu.2020.1505

ISSN: 1938-7849 | Licensed under the Creative Commons Attribution - Noncommercial License 4.0

The Journal of Transport and Land Use is the official journal of the World Society for Transport and Land Use (WSTLUR) and is published and sponsored by the University of Minnesota Center for Transportation Studies. 


\section{$1 \quad$ Introduction}

Chinese cities have undergone enormous spatial restructuring because of economic growth and urban development. The nation as a whole is in the process of rapid urbanization, and some Chinese megacities have come to the suburbanization.

In the Chinese megacities' suburbanization, residents migrate rapidly to the city's periphery. Some such migrants have relocated willingly to modernized housing or for other lifestyle reasons (Day \& Cervero, 2010). Some migrants have chosen to live on the periphery because of unacceptably high housing prices or the rising downtown rents. Others have to move outside the central city because of the centralcity substandard housing demolition and residence relocation.

To reform the old downtown area and improve living condition, substandard residential housing is demolished in the central city. The government relocates the residents (they are called relocatees in this paper) to megacity peripheral relocatees' areas (In Shanghai, these areas are called affordable large-scale residential areas on the city periphery). Chinese government has this power because the land is owned by the government, land use is regulated by the government, and there is considerable subsidy for the residents.

Such peripheral areas' development is a major part of the suburbanization in Chinese megacities and it is in a massive scale. There are approximately 30 affordable large-scale residential areas developed or planned in the suburban area of Shanghai and Beijing each (Tongji University, 2011; Liang, 2002). However, our current understanding of the public transit and transit captivity this newly developed Chinese megacity peripheral relocatees' area is still not fully developed.

In addition, after the relocation, resident's housing quality is improved. However, previous interviews and reports showed that the primary travel mode is public transit and residents find public transit in such peripheral areas unsatisfactory (Tongi University, 2011). Previous studies have indicated that public transit riders have a low level of travel satisfaction (St- Louis, Manaugh, van Lierop, \& ElGeneidy, 2014; Morris \& Guerra, 2015; De Vos, Mokhtarian, Schwanen, van Acker, \& Witlox, 2016; Ye \& Titheridge, 2017). For these newly developed areas, these public transit riders are worth studying. So in-depth public transit analytics becomes the focus of this study.

Lastly, for high population density country, "Public Transit Priority" is the national transportation development strategy. "How is the public transit in the newly developed massive Megacity Peripheral Relocatees' Area in China" becomes the research question of this study. To provide such public transit and transit captivity knowledge and support policy decision-making, this study is formed. We propose an analytical framework for this study in the methodology section and in the following sections, we 1) conduct travel mode choice statistical analysis and Integrated Choice and Latent Variable Model is estimated to study the effect of residents' transit perception on travel mode choice; 2) dive deep into understanding transit captivity issue and captive transit riders in the megacity peripheral relocatees' area. We try to answer "What are the significant differences of captive transit rider, choice transit rider, car user, and motorcycle/moped user?" and "What public transit factors are affecting the transit-service-quality subjective evaluation of the captive transit rider and overall sample?"; 3) conduct dynamic accessibility gap of public and private travel modes using multi-source heterogeneous data.

These three paragraphs above have discussed the three main study motivations, research questions, and research contents. As follows, there are several major sections: Literature Review, Methodology and Data; Analysis and Results; and Conclusion. 


\section{$2 \quad$ Literature review}

When studying transit captivity, many previous researches have focused on developed countries (Cervero, 1990; Jacques, Manaugh, \& El-Geneidy, 2013; Habib \& Weiss, 2014). These researches have divided travelers into transit captive, automobile captive, and choice users; and analyzed captive transit riders' characteristics (Cerveo, 1990; Beimborn, Greenwald, \& Jin, 2003; Papaioannou, \& Martinez, 2015). Polzin et al. observed from the Nationwide Personal Transportation Study and found that nationwide, about $30 \%$ of the population 5 years old or older was identified as transit-dependent; this portion of the population accounted for about $70 \%$ of all transit trips (Polzin, Chu, \& Rey, 2000). Literature results also show that captive users were less sensitive to fare changes than choice riders in general (Cervero, 1990); they made transit trips that were shorter in both duration and distance but lower in speed on average (Polzin et al., 2000); they were more likely to live close to bus stops (Ye \& Titheridge, 2017) and good accessibility of the system as a whole encourages public transport use but poor connectivity on a particular trip might deter it (Papaioannou \& Martinez, 2015). Using Household Activity and Travel Diary Survey data from the Portland, Oregon, Beimborn et al. (2003) found that traditional models underestimate the variation in mode choice for captive users, while overestimating the attractiveness of transit for choice users. In addition, captive riders continued to use transit but showed discontent through their ratings of service quality (Zhao, Webb, \& Shah, 2014). And people who do not travel with their preferred travel mode (e.g., captive travelers) are less satisfied with their trips compared to people who are able to travel with their preferred travel mode (De Vos, 2018).

Fewer studies looked into transit captivity in developing countries. Srinivasan et al. investigated mode choice decisions of workers in Chennai City, a metropolis in India and found that in regard to differences across captive, semi-captive, and choice segments, the choice segment was particularly more sensitive to non-motorized travel times. Furthermore, individuals with vehicles (both semi-captive and choice segments) were much more sensitive to travel times of public transportation modes than of personal vehicles (Srinivasan, Pradhan, \& Naidu, 2007). Huzayyin and Youssef (2013) investigated Greater Cairo, Egypt and stated many of the travelers in urban areas of developing countries were captives to transport modes; with limited freedom to choose the desired mode of travel.

In China, the country as a whole is a developing country and still undergoing rapid urbanization. However, some of the megacities have come to the suburbanization due to the high density in the city center. There are outward movements of urban population and industries from the city center to the city periphery. Furthermore, the city is becoming polycentric with sub-centers and industrial zones are being built in the suburbs (Tongji University, 2011). When studying travel issues of Chinese megacity peripheral residents, most previous literatures focused on these sub-centers before large-scale residential areas existed (Shen, 1997; Zhao, Lu, \& de Roo, 2011; Zhao, 2011).

China's current suburbanization is characterized by residential decentralization due to old city regeneration and the development of affordable housing in the suburbs (Tongi University, 2011; Zhou, 1997). In the central city redevelopment process, substandard housing is demolished, and the government relocates residents to the large-scale residential areas on the megacity periphery (called megacity peripheral relocatees' area in this paper). The development of the large-scale residential areas on the city periphery plays an important role in the suburbanization and become the focus of the studies.

Regarding the residents who are living in large-scale residential areas and new towns in the suburbs, most studies worked on understanding the travel issue and residents' or relocatees' travel behavior using single data source. It was found that a move to Beijing's periphery lengthened commute time more than a move to the urban core, and the "reluctant" movers had more travel time increase in average (Yang, 2006). And these areas could be generally characterized as automobile-oriented communities, with longer distance traveled. And the travel time to workplace was the highest among all different 
kinds of housing communities (Zhao, 2011). Similar results were found in Shanghai. Cervero and Day studied the impacts of the relocation to outlying areas in Shanghai, finding that job accessibility levels declined dramatically following the move, matched by increased motorized travel and longer commute durations (Day \& Cervero, 2010; Cervero \& Day, 2008; Day, 2009). So, when studying the relocatees' travel characteristics and travel behaviors, researchers indicated that relocation policy decision making should consider relocatees' travel needs as a major factor, instead of what was done in this policy making process previously (Day \& Cervero, 2010; Cervero \& Day, 2008; Day, 2009; Pan, Wang, \& Day, 2010; Guan \& Zhang, 2011; Guan, 2012, 2013; Guan \& Yang, 2015). In addition, some studies did touch upon transit captivity issue. For example, Cervero and Day found that the non-choice movers were more likely to make a non-motorized-transport-to-rail switch, possibly reflecting some degree of transit dependence and captivity (Day \& Cervero, 2010; Cervero \& Day, 2008; Day, 2009). Guan found that built environment may contribute to the suppressed travel condition in the Shanghai large-scale residential area on the city periphery (Guan, 2015). However, these studies did not conduct in-depth analysis to focus on captive transit riders.

As for transit captivity research in China, very few studies focused on its megacity's periphery. Most of the previous transit captivity researches investigated the central city areas or from an overall perspective. Deng and Nelson (2012) studies the perception of Bus Rapid Transit from a passenger survey in Beijing Southern Axis BRT Line 1 and found that the captive users had a higher satisfaction than choice users with respect to reliability, comfort and cleanliness and overall satisfaction with the BRT service. This was different from what was found in Chicago and Ghent, Belgium in the developed countries, which concluded that captive riders continued to use transit but showed discontent through their ratings of service quality (Zhao et al., 2014; De Vos, 2018). Chen (2003) analyzed the public transit privatization in China and mentioned many low-income people, including laid-off workers, were transit captive riders.

To evaluate the difference between the public travel mode and private travel mode, some studies focus on modal accessibility gap (MAG), which was proposed by Kwok and Yeh (Zhang, Shen, \& Sussman, 1999; Shen, 1998; Kwok \& Yeh, 2004). In previous study, modal accessibility gap is static and different across different built environments. For the study area of America and Europe, the accessibility of private travel mode is always better than that of public travel mode (Hess, 2005; Kawabata, 2009; Salonen \& Toivonen, 2013), while in Hong Kong the accessibility of public travel mode is much better than that of private travel mode (Kwok \& Yeh, 2004). And some other studies have focused on the factors that will influence the static modal accessibility gap, such as the characteristics of study area and the time periods when conducting the study (Yang, Chen, Cao, Li, \& Li, 2017; Mao et al., 2018). So far, we haven't found any dynamic analytics of modal accessibility gap between public and private travel modes for real-travel-covered areas using multi-source heterogeneous data.

In summary, there are many studies focusing on regular or captive transit riders and accessibility in developed countries and central city areas of developing countries. Very few of them looked into developing countries' city peripheral areas in the megacity suburbanization process, especially those megacity peripheral relocatees' areas. And for the transportation studies of this type of area, most of them focused on residents' travel characteristics, travel problems, and travel mode choice. To our knowledge, very few studies 1) conducted in-depth analysis on transit captive riders, and 2) using multi-source heterogeneous data to explore dynamic modal accessibility gap of public transit and private travel mode in the megacity peripheral relocatees' area in the developing country. To fill this research gap, this paper is formed and focuses on Shanghai the megacity in the developing country China. These two aspects above are all studied. 


\section{Data and methodology}

\subsection{Survey site}

Shanghai is a large, populous and complex megacity, which is a key instance of the Chinese megacity's suburbanization and central city redevelopment. It is chosen as the case study city. In Shanghai, the megacity peripheral relocatees' area is called Large-Scale Residential Area on the City Periphery (Guan \& Yang, 2015; Guan \&Xu, 2018). In this research, "large-scale residential area" means an area of $2 \mathrm{~km} 2$ or more, with a population of 30,000 to 50,000 , that has a major function of providing affordable housing and residence. "On the city periphery" means it is not located in the central city. In the case of Shanghai, "on the periphery" means outside Outer Ring Road (see Figure 1 in Guan \& Yang, 2015), which is the symbolic boundary between the Shanghai's central city and its suburbs.

There are approximately 30+ affordable large-scale residential areas developed or planned in the suburban area of Shanghai. As a pilot study of the large-scale residential areas on the city periphery, this research had limited funding and resource. So, we were able to pick only one area with limited samples at the time. The large-scale residential case area should have an occupancy rate of $70 \%$ or over. So, we picked Jinhexincheng.

Jinhexincheng (the name means Golden Crane New Town in Chinese. It is in Jiading District, Shanghai) is a residential area located to the west of downtown Shanghai and outside Outer Ring Road. It is approximately $2 \mathrm{~km}^{2}$. Until March 2012, the population of registered residents was approximately 28,000 .

Jinhexincheng consists of 10 developments: eight of them are for residents relocated from the central city, whose old housing was demolished (relocatees); the other two are market-rate housing. Residents are mainly relocatees, tenants who pay rents to live here, or market-rate housing owners. These 10 housing projects were completed between 2005 and 2008. Residents started to live here in 2005.

At the time of the survey, Jinhexincheng had only a few small grocery stores, limited retail shopping, and no metro service. Fourteen bus stops located in this area and five conventional bus lines connected residents to the central city and other areas. Because of the inconvenience of travel, some relocated central-city residents leased their apartments in Jinhexincheng and moved back to the city center (Tongii University, 2011).

\subsection{Sampling approach and survey data}

Because the census and other sources cannot provide a useful dataset for this kind of newly developed area at a detailed level, a field study of local transport conditions, a survey using a questionnaire, and interviews with residential committees and residents were conducted by the research team in 2011 .

A stratified sampling approach was used to select households in the 10 developments in Jinhexincheng. Approximately 400 households were contacted in the area. One person in each household (older than 12) was asked to participate (Invitation was mailed). After the process of contacting those who replied and filling in the questionnaires, 320 residents' valid questionnaires were collected with $70 \%$ to $100 \%$ questions answered. The survey response rate was quite high because the survey was approved by the Municipality of Shanghai and had residential committees' help. It is noteworthy that although the selection of the developments was non-random, the selection of the households within each development was done quasi-randomly (one household was chosen from every third floor in each access stairwell). Due to a lack of available place-specific data on housing and population demographics, the survey was done by the authors' best guess at a representative sample of the peripheral population and new housing stock. 
Respondents were asked to complete a self-reported survey, or to complete the survey with an interviewer's help, on their travel behavior, transit preference, and individual and household characteristics. Each person was asked about the one most frequent trip he or she made, the trip's purpose and choice of travel mode, and so on. Resident's one most frequent trip is the focus because it is the major and most frequent trip among all other trips one person makes. And it can be used mostly to represent commute trips for workers and shopping trips for non-workers. In addition, at this beginning stage, satisfying all travel needs is impossible because of the lack of funding and resources for this newly developed area in the developing country; satisfying the most frequent travel demand or need is the priority for now. In the future study, all trips of a regular day should be asked.

320 residents' 320 valid trips (one person, one trip) were collected. These 320 overall trips can be divided into three categories according to the different purposes of travel: 1) going to work or school and related activities are counted as subsistence travel and amounted to 161 trips; 2) going shopping for necessaries, picking up others, and going to the hospital are counted as maintenance travel and amounted to 143 trips; 3) going out for dining, entertainment, or leisure or social activities are counted as recreation travel and amounted to only 16 trips. In this study, we focus on residents' most frequent trips: subsistence and maintenance travel, rather than recreation travel. The final valid sample contains 304 residents' 304 trips, including subsistence travel (161 trips) and maintenance travel (143 trips).

\subsection{Multi-source heterogeneous data}

The multi-source heterogeneous data includes survey data and the data that is used for dynamic modal accessibility gap analysis. In this paper, it includes taxi Global Position System (GPS) data, metro smart card data, and Baidu Map point of interest (POI) data. The taxi GPS data is from Shanghai Qiangsheng taxi company. And taxi GPS and metro smart card data are both a one-week full dataset of Shanghai in April 2015.

\subsection{Analytical framework and models}

To analyze public transit in the megacity peripheral relocatees' area in the developing country, we propose an analytical framework using multi-source heterogeneous data:

1) using survey questionnaire data to conduct travel mode choice statistical analysis and to estimate an Integrated Choice and Latent Variable Model to study the effect of residents' transit perception on travel mode choice. The significant transit perception latent variable then becomes the study focus;

2) using survey questionnaire data to dive deep into analyzing the significant latent variable, which in this study leads us to transit captivity issue and captive transit riders in the megacity peripheral relocatees' area.

We try to answer:

a. how the transit captivity conditions are in different type of households, using statistical analysis and comparison;

b. what the significant differences of captive transit rider, choice transit rider, car user, and motorcycle/moped user are, using one-way ANOVA;

c. what factors are affecting the transit-service-quality subjective evaluation of the captive transit rider and overall sample, using ordinal regression model. We choose this model because the dependent variable of subject evaluation is on a Likert 1 to 5 scale. Subjective evaluation towards transit service quality is obtained by asking survey respondents to give 1 to 5 scores (very bad: 1; bad: 2; neutral: 3; good: 4; very good: 5) to the overall transit service quality and 11 different aspects of the public transport service, including the most- 
frequent trip's travel time, the most-frequent trip's travel cost, number of lines/stops, waiting time, operating hours (first and last service time), car crowdedness during peak hours, speed, perceived cost benefit (service quality considering fare that paid), transfer between different lines (time or distance), transfer with other travel modes (time or distance), and punctuality.

3) transit captivity issue leads us to conduct a dynamic modal accessibility gap analysis of public transit and private travel mode using multi-source heterogeneous data of taxi GPS data, metro smart card data, and Baidu Map point of interest data. In this step, we try to bring in a more fine-grained scale using big data analytics.

This is the analytical methodology which this paper is using by combining survey data with big data.

\section{$4 \quad$ Analysis and results}

\subsection{Travel mode share statistical and model analysis}

In the case area, there are six travel modes available: car, transit, motorcycle or moped, bicycle, shopping shuttle bus and walking. The mode shares of them in the sample for the most-frequent subsistence and maintenance trips are: $41 \%$ transit; $25 \%$ motorcycle or moped; $14 \%$ shopping shuttle bus; $10 \%$ car; $5 \%$ bicycle; and $5 \%$ walking.

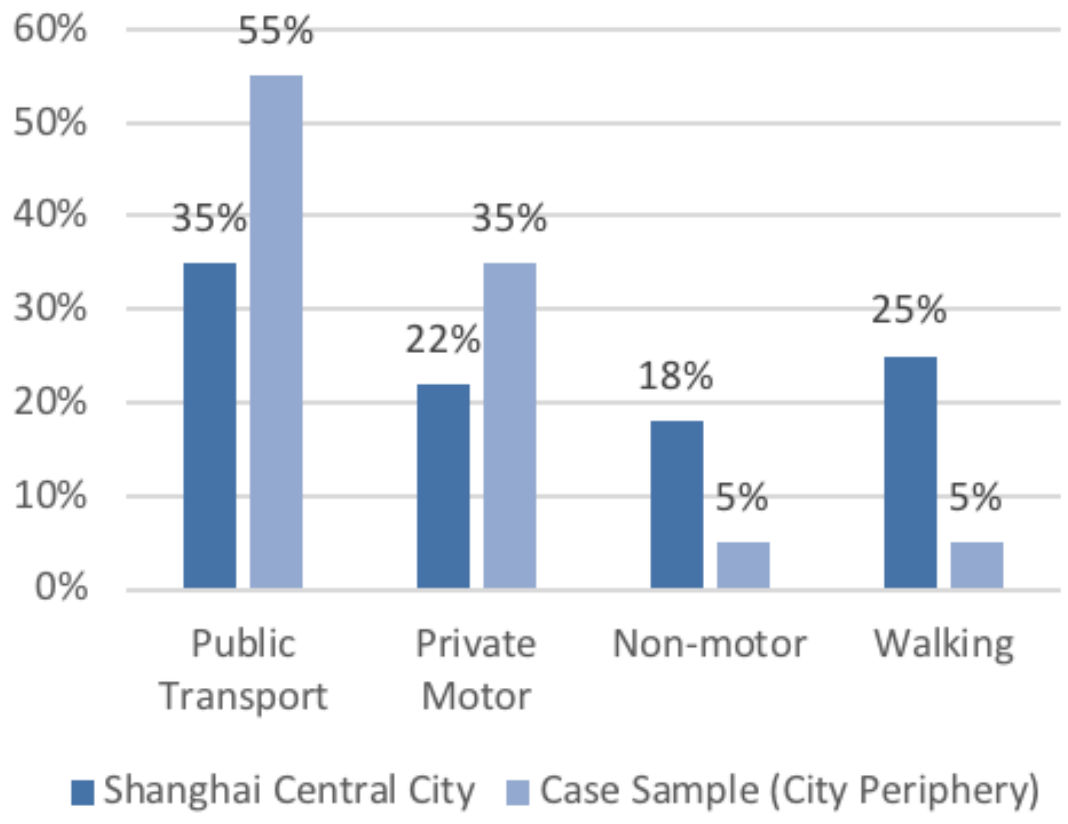

Figure 1. Mode share comparison between Shanghai central city travel diary and city-periphery case area samples' most frequent trip (in 2011)

Shanghai-central-city residents' travel mode share is shown in Fig. 1 (Shanghai Urban Rural Construction and Transportation Development Research Institute \& Shanghai City Comprehensive Transportation Planning Institute, 2014). This demonstrates that residents in the case area on the city periphery have higher public transport and private motor shares and have lower non-motor mode and walking shares, compared to residents in the city center. Please note that there is no Shanghai most-frequent-trip 
mode share data available, so this is simply showing a very rough comparison.

An Integrated Choice and Latent Variable Model is estimated in Python Biogeme (Bierlaire, 2003) to analyze the effect of transit perception on transit mode choice. It employs the simultaneous maximum likelihood estimation method. These results are consistent and have efficient estimates of the model parameters (Walker, 2001) (detailed model theory see reference Walker, 2001).

Table 1. Travel mode choice model: Integrated choice and latent variable model for subsistence and maintenance travel

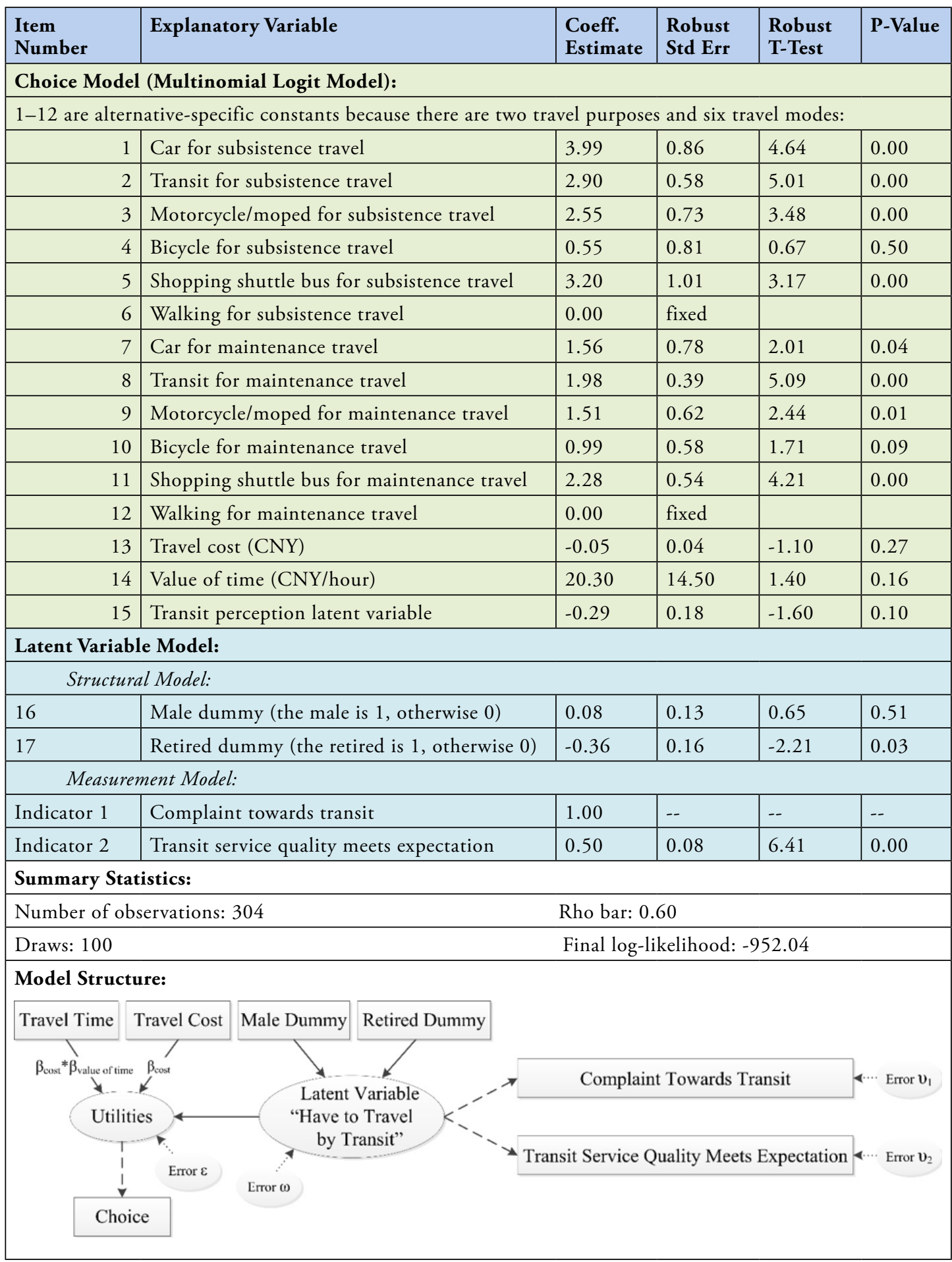


Note: Criterion for significance: $\mathrm{p}$ value $\leq 0.10$. The likelihood ratio test between multinomial logit model and this model shows that there is a 99.5 percent degree of confidence that this model is different from and better than the multinomial logit model.

Each person has one most-frequent trip in the sample in the model (Table 1). The choice set includes six travel modes: car, transit, motorcycle or moped, bicycle, shopping shuttle bus and walking. The following data entered the model: trip purpose, mode choice, alternative attributes (travel time and cost), personal attitudes towards transit, demographic characteristics.

This model has two sets of alternative-specific constants separately for subsistence and maintenance travel. With six travel modes, it has 12 alternative-specific constants in total (Table 1). The value of time is 20.3 China Yuan (CNY) per hour (CNY is the money name in China, 1 United States Dollar (USD) $=6.21 \mathrm{CNY}, 20.3 \mathrm{CNY} /$ hour $=3.27 \mathrm{USD} /$ hour at the time). In Chinese value of time literatures, the value of time is in the range of 9-34 CNY/hour (1.45-5.48 USD/hour) (Deng \& Nelson, 2012). The value of time in this model is reasonable compared to the existing literatures' Chinese value of time. The value of time is reasonable shows that this model is acceptable. However, due to the limited sample size in this pilot study, the significant level of value of time is only $84 \%$.

The significant transit perception latent variable has a negative effect on transit mode choice. Other characteristics are insignificant, and they are dropped from the model except gender (keeping only gender in the model is to match with the significant result in the comparable multinomial logit model in the bottom Note of Table 1).

The transit perception latent variable has two significant indicators: "complaint towards transit" and "whether transit service quality meets the expectation." They were asked in the questionnaire, using the Likert five-level scale. The original questions and choices are: Have you complained about public transport? Answers are from 1. All the time to 5. Not at all; Does public transport overall service quality meet your expectation? Answers are from 1. Not even close to 5. Far beyond. The effect to the "complaint towards transit" indicator is stronger.

The model results show that the resident still choose transit even when his transit perception is not good. This indicates that some transit captivity issue may exist in this area. So, it becomes the study focus of the next section.

\subsection{Transit captivity and captive transit rider analysis}

\subsubsection{Transit captivity statistical analysis and comparison}

Conventional travel behavior analysis focused on two types of transit users: captive and choice transit riders (Cervero, 1990; Jacques et al., 2013; Beimborn et al., 2003; Polzin et al. 2000; Zhao et al., 2014; Keefer, 1962; Brown, 1983; Peng, Yu, Beimborn, 2002; Krizek \& El-Geneidy, 2006). These two terms have widely been used by professionals and scholars despite the ambiguity associated with them (Jacques et al., 2013). Captive riders are typically those who lack an alternative to transit; they therefore use it as their primary mode of transportation to reach their destination. Choice riders are those who have realistic alternatives (e.g., driving) but choose to use transit for various trips (Krizek \& El-Geneidy, 2006).

Many previous researches define captive transit riders as those individuals who do not have a car available or do not have a driving license (Beimborn et al., 2003; Zhao et al., 2014; Srinivasan et al., 2007). However, even for those individuals who have a car available in the household, their car can be used mainly by their family members; therefore, they can still be captive transit riders. Whereas, for captive transit riders, they can choose not to have a car, i.e., captive by choice (Jacques et al., 2013; Papaioannou \& Martinez, 2015) and have no sense of transit captivity; so, they are not counted as captive transit riders in this study.

To understand who are captive transit riders and who are choice transit riders directly, this study asked residents a Transit Preference Question with four choices: a. having no other mode choice, I have 
to travel by transit; b. having other choices, I prefer transit; c. I enjoy riding transit very much; and $\mathrm{d}$. indifferent. And we define captive transit riders as those who choose a; choice transit riders as those who choose choice b or c.

In the sample, 41 percent of them travel by transit for their most frequent trips, which is 124 transit riders out of the overall 304 residents' sample. Among these transit riders, 71.77 percent ( 89 riders) answered the direct transit preference question with "a. having no other mode choice, I have to travel by transit." This indicates that there are over $70 \%$ captive transit riders in the transit rider sample.

Transit captivity is studied among four different types of households: motorcycle or moped available households, motorcycle or moped non-available households, car available households, and car nonavailable households. The statistical analysis and comparison is shown in Fig. 2.

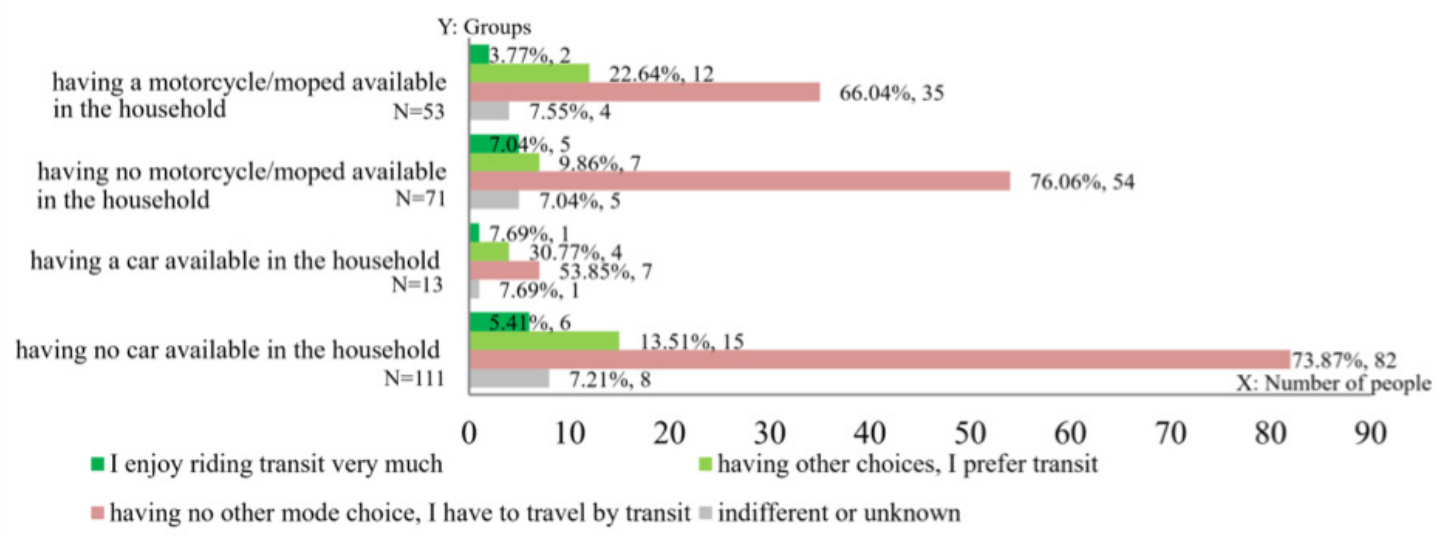

Figure 2. The answers of the transit preference question in the Jinhexincheng transit rider sample (124 transit riders)

We take a closer look at the transit rider samples who choose transit as their most frequent trips' travel mode in Fig. 2:

1) In the 124 transit rider samples, $89.52 \%$ of them (111 riders) have no car available in the household. Moreover, among the 89 transit captive rides, $92.13 \%$ ( 82 riders) has no car in the household.

To reduce car usage and traffic congestion in city center, many countries have different policies and methods. Some increase the cost of downtown parking but have a low price of car, vehicle-licensing fee and driving license cost, like in New York, San Francisco and so on. Some have congestion pricing policy in the city center, like in London. Chinese megacities have vehicle-license-restriction policy to increase the cost of having access to a car, like in Beijing, Shanghai and other major Chinese cities. This makes owning a car with its license costs too much for the residents in the megacity peripheral relocatees' area in China.

In Shanghai, car is affordable: average Shanghai employee's annual income is approximately 53,000 CNY in 2011 (Shanghai Municipal Statistics Bureau \& Shanghai Statistics Press, 2012); a new car costs about 30,000 CNY (EmaoAuto, 2012); a second-hand car is cheaper than this. However, the Shanghai vehicle license is too expensive to afford. There is a vehicle-license- restriction policy. Since 1994, Shanghai has instituted a local vehicle-license auction. Only with this local vehicle license, a car can be driven into the Shanghai central city (within the Outer Ring Road). Suburban cars with Shanghai C license are forbidden from entering the inner ring road. And cars with nonlocal licenses are forbidden from driving on the elevated expressway network in the central urban area during peak hours. In the local vehiclelicense auction, average price is approximately 50,000 CNY in 2011 (Vehicle License's Price Tendency in Shanghai, 2015), which can be used to purchase two cars.

Vehicle licensing limitation policy has suppressed car ownership in Shanghai (Chen \& Zhang, 
2012). Only 18.42 percent of the Jinhexincheng samples own cars. With this low car ownership rate, some residents have to travel by transit.

Among all six possible travel modes (car, transit, motorcycle or moped, bicycle, shopping shuttle bus and walking), shopping shuttle bus serves shopping trips; by bicycle and walking can only reach limited destinations nearby; car ownership rate is too low; so there are only transit and motorcycle/ moped left for most residents when they are traveling to the general destinations. This can explain why transit and motorcycle/moped have first and second highest mode shares. If someone does not have a motorcycle or moped available, he or she will have to travel by transit.

2) For all four groups in the axis $y$ in Figure 2, a majority of them are captive transit riders that have answered the transit preference question with "having no other mode choice, I have to travel by transit", no matter having a motorcycle/moped or car available or not.

3) "Having a car available in the household" group has the smallest percentage of captive transit riders $(53.85 \%)$. This means car availability may contribute to the transit captivity and has greater effect than motorcycle/moped.

4) When we compare the percentages of the respondents who answered that they "have other choices but prefer transit" in each of the four groups, "residents who have a car available in the household" group ranks the first with $30.77 \%$. Then it is the "residents who have a motorcycle or moped available in the household" group, with $22.64 \%$. "Residents who have no car available in the household" group comes the third with $13.51 \%$. "Residents who have no motorcycle or moped available in the household" ranks the last with $9.86 \%$. This supports that car availability may have greater contribution to the transit captivity than motorcycle/moped, too.

\subsubsection{Differences of captive transit rider, choice transit rider, car user, and motorcycle/moped user}

The presence of the transit captivity is an indication of possible transit rider loss when income increasing, and car being purchased in the future. We need to prevent this transit rider loss because: residents relying on private travel modes rather than public transport will cause serious traffic congestion and pollution for high population density megacities. So, it is essential to understand the captive transit riders' characteristics in the area. Then we can give captive-transit-rider related policy suggestions to the public transit improvement.

In this section, we study the characteristics' mean difference of four groups of people in the overall samples of 304 residents: captive transit rider (sample size: 89); choice transit rider (sample size: 26); car user (sample size: 32); and motorcycle/moped user (sample size: 76). Previously in the "Transit Captivity Statistical Analysis and Comparison" section of this paper, we mentioned the definition of captive transit rider and choice transit rider. Meanwhile, we asked the residents the one most frequent trip's choice of travel mode. Residents who choose car are counted as car users and residents who choose motorcycle or moped are counted as motorcycle/moped users.

We analyze the characteristics of demographics, transport-related decisions (driving license, car desire...), subjective evaluation towards public transport, and availabilities of the travel modes to see if there is significant mean difference among the four groups (captive transit rider, choice transit rider, car user, and motorcycle/moped user). Each group's mean and standard deviation of different characteristics are calculated; the significance of the mean difference is analyzed using one-way ANOVA. Significant results are shown in Table 2 .

There are significant characteristics' mean differences of the four groups (Table 2). Other characteristics, which are not shown in the table, are no statistically significant differences between group means. Among the four groups, captive transit riders are the ones that are older, more female, more 
non-working, more retired, more that owning apartment, less having driving license, less satisfied with waiting time, most-frequent trip's travel time, and the average of the 11 different aspects of transit service, and having more complaint towards the public transport. When making policies on public transit, we should consider these characteristics differences of the captive transit riders and others.

Table 2. Characteristics' mean difference of four groups of resident samples: 89 captive transit riders; 26 choice transit riders; 32 car users; and 76 motorcycle/moped users (one-way ANOVA, mean difference with significance at the 0.05 level)

\begin{tabular}{|c|c|c|c|c|}
\hline \multirow{2}{*}{$\begin{array}{l}\text { Items } \\
\text { Groups }\end{array}$} & \multicolumn{4}{|c|}{ (Ranking of the mean magnitudes from the highest) Mean, Standard Deviation } \\
\hline & Captive transit rider & Choice transit rider & Car user & Motorcycle/moped user \\
\hline Age (years old) & (1) $44.49,16.92$ & (2) $42.00,15.90$ & (4) $35.06,9.74$ & (2) $42.00,14.08$ \\
\hline $\begin{array}{l}\text { Gender } \\
\text { (male: } 1 \text {; female: } 0 \text { ) }\end{array}$ & (4) $0.48,0.50$ & (3) $0.58,0.50$ & (1) $0.78,0.42$ & (2) $0.66,0.48$ \\
\hline $\begin{array}{l}\text { Education (< high school: 1; high } \\
\text { school: 2; technical school: 3; bach- } \\
\text { elor's: 4; master's: 5; PhD: 6.) }\end{array}$ & (3) $2.53,1.09$ & (2) $2.62,1.20$ & (1) $2.84,1.39$ & (4) $2.28,0.93$ \\
\hline $\begin{array}{l}\text { Working status } \\
\text { (working: } 1 \text {; others: } 0 \text { ) }\end{array}$ & (4) $0.60,0.49$ & (3) $0.65,0.49$ & (1) $0.94,0.25$ & (2) $0.66,0.48$ \\
\hline $\begin{array}{l}\text { Retirement } \\
\text { (retired: } 1 \text {; others: } 0 \text { ) }\end{array}$ & (1) $0.26,0.44$ & (3) $0.08,0.27$ & (4) $0.00,0.00$ & (2) $0.18,0.39$ \\
\hline $\begin{array}{l}\text { Apartment ownership } \\
\text { (own: } 1 \text {; others: } 0 \text { ) }\end{array}$ & (1) $0.78,0.42$ & (2) $0.73,0.45$ & (4) $0.56,0.50$ & (3) $0.58,0.50$ \\
\hline $\begin{array}{l}\text { Driving license } \\
\text { (yes: } 1 \text {; others: } 0 \text { ) }\end{array}$ & (4) $0.15,0.36$ & (2) $0.24,0.44$ & (1) $0.78,0.42$ & (3) $0.23,0.42$ \\
\hline $\begin{array}{l}\text { Car availability } \\
\text { (available: } 1 \text {; others: } 0 \text { ) }\end{array}$ & (3) $0.08,0.27$ & (2) $0.19,0.40$ & (1) $1.00,0.00$ & (4) $0.03,0.16$ \\
\hline Motorcycle/moped availability & (3) $0.39,0.49$ & (2) $0.54,0.51$ & (4) $0.34,0.48$ & (1) $1.00,0.00$ \\
\hline Bicycle availability & (2) $0.39,0.49$ & (1) $0.50,0.51$ & (3) $0.28,0.46$ & (4) $0.17,0.38$ \\
\hline $\begin{array}{l}{ }^{*} \text { Score of } \\
\text { waiting time }\end{array}$ & (4) $2.67,1.10$ & (3) $2.77,1.03$ & (1) $3.27,1.02$ & (2) $2.99,1.03$ \\
\hline $\begin{array}{l}\text { Score of } \\
\text { operating hours } \\
\text { (first and last service time) }\end{array}$ & (3) $2.64,1.16$ & (4) $2.38,1.13$ & (1) $3.34,1.08$ & (2) $2.84,1.07$ \\
\hline $\begin{array}{l}\text { Score of } \\
\text { punctuality }\end{array}$ & (3) $3.07,0.93$ & (4) $3.04,1.10$ & (1) $3.55,0.74$ & (2) $3.21,0.85$ \\
\hline $\begin{array}{l}\text { Score of } \\
\text { most-frequent trip's travel time }\end{array}$ & (4) $2.21,0.97$ & (3) $2.58,0.95$ & (1) $2.94,1.01$ & (2) $2.88,0.91$ \\
\hline $\begin{array}{l}\text { Each individual's mean } \\
\text { of } 11 \text { scores of } \\
11 \text { public-transport-service aspects* }\end{array}$ & (4) $2.72,0.55$ & (3) $2.85,0.76$ & (1) $3.06,0.54$ & (2) $2.97,0.52$ \\
\hline $\begin{array}{l}\text { Have you complained about public } \\
\text { transport? Likert five-level scale from } 1 \text {. All } \\
\text { the time to } 5 \text {. Not at all }\end{array}$ & (4) $3.01,1.23$ & (3) $3.42,1.10$ & (1) $3.69,1.03$ & (2) $3.62,0.97$ \\
\hline
\end{tabular}




\subsection{Subjective evaluation towards public transit: Regression model analysis}

The presence of the transit captivity is an indication of possible transit rider loss when income increasing, and car being purchased in the future. So, it is essential to understand the captive transit riders, especially their subjective evaluation towards different aspects of public transit service. Then we can give relative policy suggestions to the public transit improvement in the area.

In this section, we estimate ordinal regression models to understand what contributes to the subjective evaluation towards public transport's overall service quality. And policy suggestions are given, regarding which aspect of the transit service should to be improved with a high priority, given the differences of captive transit riders and others.

The subjective evaluation towards transit service quality is obtained by asking survey respondents to give 1 to 5 scores (very bad: 1; bad: 2; neutral: 3; good: 4; very good: 5) to the overall transit service quality and 11 different aspects of the public transport service, including the most-frequent trip's travel time, the most-frequent trip's travel cost, number of lines/stops, waiting time, operating hours (first and last service time), car crowdedness during peak hours, speed, perceived cost benefit (service quality considering fare that paid), transfer between different lines (time or distance), transfer with other travel modes (time or distance), and punctuality.

According to Shanghai Quality Association's survey of 2211 respondents, the average public transport satisfaction score is 80.13 in Shanghai (Chen, 2012) while in our survey, it is only 60. Only 18.55 percent of the transit riders find transit overall service quality good in our survey. This may be related to the transit or transport service level in peripheral areas being not as good as in the city center. Overall resident samples subjectively evaluated public transit and its 11 different service aspects between bad and neutral. This proves that the transit service needs to be improved in the large-scale residential areas on the megacity periphery.

What contributes to the subjective evaluation towards public transport's overall service quality? To answer this, we estimate ordinal regression models. The dependent variable is each respondent's subjective evaluation score towards public transport's overall service quality. We started by running the identical model and then dropped the insignificant variables. The following survey data was entered as the independent variable into the model: demographic characteristics (age, gender, retirement, apartment ownership, relocatee or not, years living locally,...), transport-related characteristics (car ownership, driving license, car desire, bicycle ownership,...), subjective evaluation scores towards public transit and its different aspects, four groups dummy variables (captive transit rider, choice transit rider, car user, and motorcycle/moped user), and availabilities of the travel modes.

Two significant ordinal regression models are shown in Table 3. Model A has interactions of different characteristics and "captive transit riders and others"; model B uses the overall samples with no interaction. 
Table 3. Factors that affect subjective evaluation toward public transit's overall service quality" (ordinal regression model)

\begin{tabular}{|c|c|c|c|c|c|c|c|c|}
\hline \multirow{2}{*}{\multicolumn{3}{|c|}{ Variable's Name }} & \multicolumn{3}{|c|}{$\begin{array}{l}\text { Model A: captive transit riders (cap- } \\
\text { tive) and others: respectively interacted } \\
\text { with the explanatory variables }\end{array}$} & \multicolumn{3}{|c|}{ Model B: all valid samples } \\
\hline & & & $\begin{array}{l}\text { Parameter } \\
\text { Estimate }\end{array}$ & Std. Error & Sig. & $\begin{array}{l}\text { Paramet-er } \\
\text { Est. }\end{array}$ & Std. Error & Sig. \\
\hline \multirow{4}{*}{\multicolumn{2}{|c|}{$\begin{array}{l}\text { Threshold: } \\
\text { Subjective Evaluation towards } \\
\text { Public Transit's Overall } \\
\text { Service Quality }\end{array}$}} & Score $=1$ & -0.62 & 0.96 & 0.52 & 0.78 & 0.56 & 0.16 \\
\hline & & Score $=2$ & 1.85 & 0.94 & 0.05 & 3.20 & 0.53 & 0.00 \\
\hline & & Score $=3$ & 4.59 & 0.98 & 0.00 & 5.88 & 0.62 & 0.00 \\
\hline & & Score $=4$ & 9.77 & 1.42 & 0.00 & 11.01 & 1.21 & 0.00 \\
\hline \multirow{9}{*}{$\begin{array}{l}\text { Subjective } \\
\text { Evaluation } \\
\text { of }\end{array}$} & \multirow{2}{*}{$\begin{array}{l}\text { Number of lines } \\
\text { or stops }\end{array}$} & Captive & 0.16 & 0.23 & 0.47 & \multirow{2}{*}{0.25} & \multirow{2}{*}{0.13} & \multirow{2}{*}{$0.06^{*}$} \\
\hline & & Others & 0.33 & 0.17 & $0.06^{*}$ & & & \\
\hline & Operating hours & Captive & 0.32 & 0.20 & 0.12 & \multirow[b]{2}{*}{0.37} & \multirow[b]{2}{*}{0.12} & \multirow[b]{2}{*}{$0.00^{*}$} \\
\hline & $\begin{array}{l}\text { (first and last } \\
\text { service time) }\end{array}$ & Others & 0.50 & 0.14 & $0.00^{*}$ & & & \\
\hline & \multirow{2}{*}{ Waiting time } & Captive & 0.32 & 0.23 & 0.15 & \multirow{2}{*}{0.51} & \multirow{2}{*}{0.14} & \multirow{2}{*}{$0.00^{*}$} \\
\hline & & Others & 0.85 & 0.17 & $0.00^{*}$ & & & \\
\hline & Speed & All & & N/A & & 0.47 & 0.16 & $0.00^{*}$ \\
\hline & \multirow{2}{*}{$\begin{array}{l}\text { Transfer with } \\
\text { other travel modes }\end{array}$} & Captive & 0.49 & 0.24 & $0.04^{*}$ & \multirow{6}{*}{\multicolumn{3}{|c|}{ N/A }} \\
\hline & & Others & 0.08 & 0.19 & 0.70 & & & \\
\hline \multirow{2}{*}{\multicolumn{2}{|c|}{ Having a bicycle available: Yes }} & Captive & 0 & -- & --* & & & \\
\hline & & Others & -1.85 & 1.2 & 0.11 & & & \\
\hline \multirow{2}{*}{\multicolumn{2}{|c|}{ Having a bicycle available: No }} & Captive & -0.91 & 0.44 & $0.04^{*}$ & & & \\
\hline & & Others & -1.57 & 1.15 & 0.17 & & & \\
\hline \multicolumn{9}{|l|}{ Summary: } \\
\hline \multicolumn{3}{|c|}{$\mathrm{N}$ (valid sample size) } & \multicolumn{3}{|c|}{$\begin{array}{c}285 \text { (84 captive transit riders and } 201 \\
\text { other samples) }\end{array}$} & \multicolumn{3}{|c|}{285} \\
\hline & \multicolumn{3}{|c|}{$\begin{array}{r}0.31 \\
0.00 \\
\end{array}$} & \multicolumn{3}{|c|}{$\begin{array}{l}0.29 \\
0.00\end{array}$} \\
\hline \multicolumn{9}{|c|}{$\begin{array}{l}\text { The dependent variable is respondents' answers to the survey question of the subjective evaluation towards public transit's overall } \\
\text { service quality. Respondents gave } 1 \text { to } 5 \text { scores to different aspects of the public transport service: } 1 \text { is very bad, } 2 \text { is bad, } 3 \text { is } \\
\text { neutral, } 4 \text { is good, and } 5 \text { is very good. } \\
\text { Link function: Logit; } \quad * \text { shows the significant one which is with Sig. }<0.1 \text {. }\end{array}$} \\
\hline
\end{tabular}

In model A, results show that: For non-captive transit riders, the subjective evaluation of waiting time, operating hours, and number of lines or stops (ranks from highest to lowest effect) have a positive and significant effect on the subjective evaluation towards public transport's overall service quality. These aspects matter for non-captive transit riders when evaluating public transport's overall service quality. Other factors that are not significant are not included in the model.

For captive transit riders, (1) the subjective evaluation of "transfer with other travel modes" have a positive and significant effect on the subjective evaluation towards public transport's overall service quality. This shows that captive transit riders thinking highly of the "transfer with other travel modes" contributes positively to their subjective evaluation towards public transport's overall service quality. We do not find subjective evaluations on other aspects of transit have this effect. (2) Captive transit riders with no bicycle available tend to have a lower score towards public transport's overall service quality. This may be related to having a bicycle available makes public transport easier to access then people may evaluate public transport's overall service quality better.

Both of these findings from the model imply that the access to the public transit matters a lot when 
captive transit rider evaluating the public transit service. This can be explained in this way: captive transit riders having no other options and they have to travel by transit. Then the waiting time, operating hours, and number of lines or stops of transit, which matter to non-captive riders, do not matter that much anymore. Having an easy access to public transit matters much more.

These results of model A have some policy implications. For captive transit riders, to increase their subjective evaluation towards public transport's overall service quality, transit's transfer condition with other travel modes should be improved. And bicycle availability contributes to the subjective evaluation towards public transport's overall service quality. It should be improved. This shows that bicycle sharing programs that serve as transit's transfer mode may help to increase captive transit riders' subjective evaluation towards public transport's overall service quality.

In model $\mathrm{B}$, overall samples are the focus. We find that the subjective evaluation of waiting time, speed, operating hours, and number of lines or stops (ranks from highest to lowest effect) have a positive and significant effect on the subjective evaluation towards public transport's overall service quality. Other results are not significant. This may be related to non-captive transit riders having other travel mode options and they do not value transfer and access to transit station that much. So, transfer and bike availability, which are found significant for captive transit riders in model $\mathrm{A}$, are not significant for the overall samples. This shows that to increase residents' subjective evaluation towards public transport's overall service quality in the large-scale residential area on the city periphery, waiting time, speed, operating hours, and number of lines or stops (ranks from high to low priority) are the ones that should have a high priority in the transit improvement.

\subsubsection{Dynamic modal accessibility gap (DMAG) analysis}

Dynamic modal accessibility gap of public transit and private travel mode is computed using multisource heterogeneous data of taxi GPS data, metro smart card data, and Baidu Map point of interest data. In this section, we bring in a more fine-grained scale using big data analytics.

Previously, Model B with the overall valid samples indicates that the subjective evaluation of waiting time, speed, and operating hours are the top three explanatory variables that have a positive and significant effect on the subjective evaluation towards public transport's overall service quality. This shows time dimension is the most important factor. So, when computing the dynamic modal accessibility gap, we use the number of POIs within the origin-travel-time-based 30min and 60min real-travel-covered areas, which are obtained using taxi GPS data and metro smart card data. The origin in the case is Jinhexincheng. The gap is measured using $\mathrm{X} / \mathrm{Y}$, where $\mathrm{X}$ is the number of POIs reachable by public transit (using metro to represent) minus the number of POIs reachable by private travel mode (using taxi to represent); $\mathrm{Y}$ is the number of POIs reachable by public transit (using metro to represent) plus the number of POIs reachable by private travel mode (using taxi to represent). The range of the DMAG index is between -1 and +1 . When DMAG $=-1$, it indicates that there is no public transit and private travel mode becomes the main travel mode. It is reverse when $\mathrm{DMAG}=1$.

It is worth mentioning that the survey was conducted in 2011 in Jinhexincheng, Shanghai but the only available Shanghai metro and taxi big data we can find is in 2015. We can only take the results in this study as the condition in the 2011-2015 years. In addition, in order to match the metro condition in 2011 and 2015, when calculating DMAG index for Jinhexincheng (Fig. 3), we do not use the Jinyun $\mathrm{Rd}$ metro station, which is the closest metro station to Jinhexincheng in 2015 but does not exist at the time of the survey in 2011. Instead, Songhong Rd metro station is used, which is the closest metro station at the time of the survey in 2011. So in DMAG index calculation, the origin-based 30min and $60 \mathrm{~min}$ real-travel-covered areas by metro is actually from Songhong Rd metro station (origin) $15 \mathrm{~min}$ and $45 \mathrm{~min}$ by-metro real-travel-covered areas, considering $15 \mathrm{~min}$ access time from Jinhexincheng to the closest metro station (Songhong Rd metro station) at the time of the questionnaire survey in 2011. 


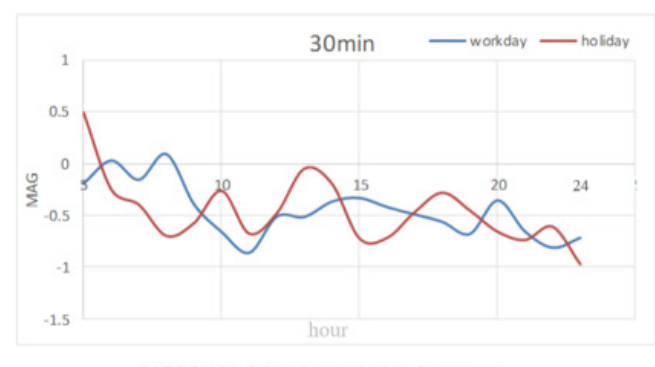

(a)DMAG of 30min real-travel covered area in JinheXincheng community

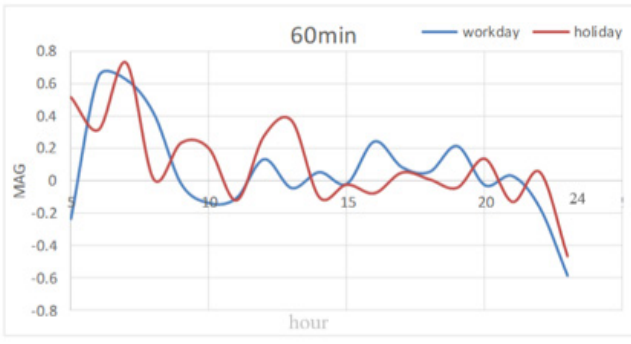

(b)DMAG of $60 \mathrm{~min}$ real-travel covered area in JinheXincheng community

Figure 3. Dynamic modal accessibility gap (DMAG) of 30-min, real-travel covered area and 60-min, real-travel covered area for workdays and holidays (taxi vs metro)

When the DMAG index is negative, it means by private travel mode, people have a better POIs accessibility. For 30min real-travel-covered area (Fig. 3 left), it is mostly negative for both workday and holiday. This indicated that for the megacity peripheral relocatees' area, mostly, by private travel mode, a person has a better POIs accessibility for the 24 hours, within which the DMAG index fluctuates. When it is $5 \mathrm{am}$ in the holiday, not many people are using taxi, but metro is being used, so the index becomes positive a bit. For $60 \mathrm{~min}$ real-travel-covered area (Fig. 3 right), mostly, by public transit, a person has a better POIs accessibility. Both figures show the DMAG index fluctuates for the 24 hours of the day. And in the midnight, there is no public transit, so the index is negative. Using big data analytics, we bring in a more fine-grained scale to analyze public transit. Together with survey data above analyzing subject evaluation factors and captive transit rides, they complemented each other nicely. So, using multi-source heterogeneous data is very helpful.

\section{Conclusion}

Chinese central-city sub-standard housing demolition and peripheral relocation create a massive megacity peripheral relocatees' areas. In these areas, public transit is the primary mode of travel and follows the nationwide "Transit Priority" strategy. However, residents in the large-scale residential area on Chinese megacity's periphery often find public transit unsatisfactory. So far, the understanding of public transit in these areas is not fully explored and developed. So, in this study, residents' transit captivity and dynamic modal accessibility gap of public transit and private travel mode are analyzed. And transit improvement suggestions are provided.

We conducted a field study of local transport conditions, a survey using a questionnaire, and interviews with residential committees and residents in one of these areas in Shanghai, China. And other Shanghai big data were gathered as well, including taxi GPS, metro smart card, and Baidu Map point of interest data. An analytical framework using multi-source heterogeneous data is proposed. The framework and results are as follows.

1) Using survey questionnaire data, we conduct travel mode choice statistical analysis and estimate an Integrated Choice and Latent Variable Model to study the effect of residents' transit perception on travel mode choice. A significant transit perception latent variable is found and leads to transit captivity issue and captive transit rider analysis in the megacity peripheral relocatees' area in this study.

2) Using survey questionnaire data, we dive deep into understanding transit captive riders through statistical analysis and comparison; one-way ANOVA; and ordinal regression model. We find that among the transit riders, $71.77 \%$ answered the direct transit preference question with "having no other mode choice, I have to travel by transit." They are defined as captive transit riders in this paper. $89.52 \%$ 
of transit rider samples and $92.13 \%$ of transit captive rides have no car in the household. No matter having a motorcycle/moped or car available in the household or not, a majority of the samples are captive transit riders. "Having a car available in the household" group has the smallest percentage of captive transit riders, compared to residents who have a motorcycle or moped available in the household.

Furthermore, the differences of captive riders and others are analyzed using mean-difference test, one-way ANOVA. Captive transit riders are the ones that are older, more female, more non-working, more retired, more that owning apartment, less having a driving license, less satisfied with waiting time, most-frequent trip's travel time, and the average of the 11 different aspects of transit service, and having more complaint towards the public transport.

In addition, we estimate ordinal regression models to understand what contributes to the subjective evaluation towards public transport's overall service quality transit, considering captive transit riders. Results show that for the overall transit service quality, the evaluation score is between bad and neutral. The transit service in the area needs to be improved. And among all different aspects of the transit service, the improvement of waiting time, speed, operating hours, and number of lines or stops of transit should have a high priority. As for captive transit riders, we should focus on the improvement of transit's transfer condition with other travel modes and making bicycle available to them. Bicycle sharing program near bus stop or metro station that serves as a transit's transfer mode may help to increase captive transit riders' subjective evaluation towards public transport's overall service quality. Hopefully with these policy suggestions and transit improvement projects, future transit rider loss can be avoided.

The authors suggest that in order to improve the attractiveness of transit in the megacity peripheral area, the city should develop a multi-level transit service instead of the current single-level traditional public transit service. So the residents can choose from a variety of multi-level regular and on-demand travel modes, including car, taxi, carsharing, carpool, ridesharing, customized on-demand bus, certainfrequency shuttle bus to city center, shopping center, metro station, or airport, and metro, bus rapid transit, regular bus, moped or bicycle share, ranking from the "most expensive and best service quality" ones to the "cheapest and worst quality" ones. With multi-level transit, residents in the peripheral areas can have more options and the subjective evaluation of public transport's waiting time, speed, operating hours, number of lines or stops, and transfer can become better.

3) The transit captivity issue leads us to conduct a dynamic modal accessibility gap analysis of public transit and private travel mode using multi-source heterogeneous data. This brings in a more fine-grained scale using big data analytics.

Previously, ordinal regression model with the overall valid samples indicates that the subjective evaluation of waiting time, speed, and operating hours are the top three explanatory variables that have a positive and significant effect on the subjective evaluation towards public transport's overall service quality. This shows time dimension is the most important factor. So, when computing the dynamic modal accessibility gap, we use the number of POIs within the origin-travel-time-based $30 \mathrm{~min}$ and $60 \mathrm{~min}$ real-travel-covered areas. Result shows that for the megacity peripheral relocatees' area, by private travel mode, a person mostly has a better POIs accessibility for the $30 \mathrm{~min}$ real-travel-covered area for the 24 hours of the average day. For $60 \mathrm{~min}$ real-travel-covered area, by public transit, a person mostly has a better POIs accessibility. The DMAG index fluctuates during different time of the day.

In conclusion, there are three main contributions in this paper: a) We find many significant characteristics of the captive transit riders. They are being older, more female, more non-working, more retired, more that owning apartment, less having a driving license, less satisfied with waiting time, mostfrequent trip's travel time, and the average of the 11 different aspects of transit service, and having more complaint towards the public transport. b) Factors contribute to the subjective evaluation towards public transport's overall service quality transit being bad to neutral are found, considering captive transit 
riders. And transit improvement policy suggestions are provided. c) Using big data analytics, we bring in a more fine-grained scale to analyze public transit. DMAG index is computed. Together with survey data above analyzing subject evaluation factors and captive transit rides, they complemented each other. So, using multi-source heterogeneous data is very helpful.

This study focuses on public transit and residents' transit captivity in the megacity peripheral relocatees' area in the developing country. Such study method and study process can be applied to many other similar areas. The understanding of captive transit riders and DMAG provide transit improvement suggestions to support the decision-making of public transit development in developing countries' similar areas.

There are limits to this study that await further research. For example, 1) more valid data and samples should be collected to provide more solid and significant results. The survey and the big data used in this study are not from the same year. So, we can only view the results of this paper as the condition in the year of 2011 to 2015 . Future work can be focused on how to use different available datasets at different time to represent conditions at a given point in time. 2) More specific transit service analysis and relevant improvement suggestions should be focused on. 3) The questionnaire survey focuses on public transit, which includes both metro and bus. However, we do not have Shanghai bus big data available, so in the DMAG calculation, only metro is used to represent public transport and bus is not included. In the future, if the bus dataset is available, bus should be taken into DMAG index calculation besides metro. 4) Time series data needs to be collected to evaluate the transit-captivity change over time in the developing country.

\section{Acknowledgements}

The author thanks Joan Walker and Akshay Vij of the University of California Berkeley; Lisa D'Ambrosio, Joseph Coughlin, Moshe Ben-Akiva and Jinhua Zhao of the Massachusetts Institute of Technology for their suggestions and feedback. The author also thanks Dongyuan Yang and his Tongji University research team for their contributions in recruiting survey participants and conducting the survey. This research is supported by the Major Project of Chinese National Programs for Fundamental Research and Development (2015CB352400) and Science and Technology Planning Project of the Ministry of Housing and Urban-Rural Development of P. R. China (2018-K8-019). 


\section{References}

Beimborn, E., Greenwald, M., \& Jin, X. (2003). Accessibility, connectivity, and captivity—impacts on transit choice. Transportation Research Record, 1835, 1-9.

Bierlaire, M. (2003). BIOGEME: A free package for the estimation of discrete choice models, Proceedings of the 3rd Swiss Transportation Research Conference, Ascona, Switzerland.

Brown, M. (1983). Public transit fare and subsidy policy in greater Vancouver, 1970-1983: Efficiency and equity implications. Vancouver, BC: School of Community and Regional Planning, University of British Columbia.

Cervero, R. (1990). Transit pricing research: A review and synthesis. Transportation, 17, 117-139.

Cervero, R., \& Day, J. (2008). Suburbanization and transit-oriented development in China. Transport Policy, 15, 315-323.

Chen, X. (2003). Retrospect and prospect of public transit privatization in China, Journal of Advanced Transportation, 37(3), 319-347.

Chen, X. (2012). Shanghai public transport satisfaction score is over 80, nearly $90 \%$ residents rely on public transport, Liberation Daily. Retrieved from www.gov.cn/gzdt/2012-10/22/content_2248482. htm.

Chen, X., \& Zhang, H. (2012). Evaluation of effects of car ownership policies in Chinese megacities: Beijing and Shanghai. Transportation Research Record, 2317, 32-39.

Day, J. (2009). Cost of suburbanization: Comparative effects of peri-urban residential relocation on household welfare measures in Shanghai (Doctoral dissertation), University of California, Berkeley.

Day, J., \& Cervero, R. (2010). Effects of residential relocation on household and commuting expenditures in Shanghai, China. International Journal of Urban and Regional Research, 34, 481-508.

Deng T., \& Nelson, J. (2012). The perception of bus rapid transit: A passenger survey from Beijing Southern Axis BRT Line 1. Transportation Planning and Technology, 35(2), 201-219.

De Vos, J., Mokhtarian, P. L., Schwanen, T., Van Acker, V., \& Witlox, F. (2016). Travel mode choice and travel satisfaction: Bridging the gap between decision utility and experienced utility. Transportation, 43(5), 771-796.

De Vos, J. (2018). Do people travel with their preferred travel mode? Analyzing the extent of travel mode dissonance and its effect on travel satisfaction. Transportation Research Part A, 117, 261-274.

EmaoAuto. (2012). Various car prices. Retrieved from http://auto.emao.com.

Guan, J., \& Zhang, P. (2011). The Shanghai periphery large-scale residential area residents' commuting characteristics: Case study of Jinhexincheng, Jiangqiao, Jiading district, Paper presented at the 2011 Annual Meeting of China Urban Transport Planning, Wuhan, China.

Guan, J. (2012). Travel characteristics of different social groups in large-scale residential areas in the periphery of Shanghai: A case study of Jinhexincheng. Paper presented at the 12th Chinese Overseas Transportation Association International Conference of Transportation Professionals (CICTP 2012, ASCE publication), Beijing, China.

Guan, J. (2013). Travel behavior of two major groups in large scale residential areas in the periphery of Shanghai: A case study of Jinhexincheng, Jiading district. Paper presented at 92nd Annual Meeting of the Transportation Research Board, Washington, D.C.

Guan, J. (2015). Travel behavior characteristics of different social groups in large-scale residential areas on city periphery: Case study of Shanghai, China (Doctoral dissertation). Tongji University, Shanghai, China.

Guan, J., \& Yang, D. (2015). Residents' characteristics and transport policy analysis in large-scale residential areas on a city periphery: Case study of Jinhexincheng, Shanghai, China. Transportation Research Record, 2512, 11-21. 
Guan, J. \& Xu, C. (2018). Are relocatees different from others? Relocatees' travel mode choice and travel equity analysis in large-scale residential areas on the periphery of megacity Shanghai, China Transportation Research Part A: Policy and Practice, 111(C), 162-173.

Habib, K., \& Weiss, A. (2014). Evolution of latent modal captivity and mode choice patterns for commuting trips: A longitudinal analysis using repeated cross-sectional datasets, Transportation Research Part A, 66, 39-51.

Hess, D. B. (2005). Access to employment for adults in poverty in the Buffalo-Niagara region. Urban Studies, 42(7), 1177-1200.

Huzayyin, A., \& Youssef, A. (2013). Analysis of the evolution of travelers' mode captivity using logit modelling; with application on Greater Cairo. Paper presented at the 13th World Conference on Transportation Research Society, Rio de Janeiro.

Jacques, C., Manaugh, K., \& El-Geneidy, A. (2013). Rescuing the captive [mode] user: An alternative approach to transport market segmentation. Transportation, 40, 625-645.

Kawabata, M. (2009). Spatiotemporal dimensions of modal accessibility disparity in Boston and San Francisco. Environment and Planning A, 41(1), 183-198.

Keefer, L. E. (1962) Characteristics of captive and choice transit trips in the Pittsburgh metropolitan area. 41st Annual Meeting of the Highway Research Board, 347, 24-33.

Krizek, K., \& El-Geneidy, A. (2006). Better understanding the potential market of metro transit's ridership and service (report no. CTS 06-09). Retrieved from its.umn.edu/Publications/ResearchReports/ reportdetail.html?id=1118.

Kwok, R. C. W. \& Yeh, A. G. O., (2004). The use of modal accessibility gap as an indicator for sustainable transport development. Environment and Planning A: Economy and Space, 36(5), 921-936.

Liang, Q. (2002). 30 affordable housing projects are developed, Beijing has no dilapidated building in 2005. Retrieved from people.com.cn/GB/shenghuo/81/99/20021124/873097.html

Mao, H., Fan, X., Guan, J., Chen, Y.-C., Su, H., Shi, W., ... Xu, C. (2019). Customer attractiveness evaluation and classification of urban commercial centers by crowd intelligence. Computers in $\mathrm{Hu}$ man Behavior, 100, 218-230.

Morris, E. A., \& Guerra, E. (2015). Mood and mode: Does how we travel affect how we feel? Transportation, 42(1), 25-43.

Pan, H., Wang, X., \& Day, J. (2010). Travel characteristics and its impact on social segregation and urban livability. Urban Planning Forum, 6, 61-67.

Papaioannou, D., \& Martinez, L. (2015). The role of accessibility and connectivity in mode choice. A structural equation modeling approach, 18th Euro Working Group on Transportation, EWGT 2015, July 2015, Delft, The Netherlands. Transportation Research Procedia, 10, 831-839.

Peng, Z., Yu, D., \& Beimborn, E. (2002). Transit user perceptions of the benefits of automatic vehicle location. Transportation Research Record, 1791, 127-133.

Polzin, S., Chu, X., \& Rey, J. (2000). Density and captivity in public transit success: Observations from the 1995 nationwide personal transportation study. Transportation Reseach Record, 1735, 10-18.

Salonen, M. \& Toivonen, T., (2013). Modelling travel time in urban networks: Comparable measures for private car and public transport. Journal of Transport Geography, 31, 143-153.

Shanghai Municipal Statistics Bureau \& Shanghai Statistics Press. (2012). Shanghai Statistical Yearbook. Shanghai: Shanghai Municipal Statistics Bureau, Shanghai Statistics Press.

Shanghai Urban Rural Construction and Transportation Development Research Institute and Shanghai City Comprehensive Transportation Planning Institute. (2014). Shanghai Comprehensive Transportation Annual Report 2014. Shanghai: Shanghai Urban Rural Construction and Transportation Development Research Institute and Shanghai City Comprehensive Transportation Planning Institute. Retrieved from wenku.baidu.com/view/5922ec06ł46527d3250ce047.html. 
Shen, Q. (1997). Urban transportation in Shanghai, China: Problems and planning implications. International Journal of Urban and Regional Research, 21, 589-606.

Shen, Q. (1998). Location characteristics of inner-city neighborhoods and employment accessibility of low-wage workers. Environment and Planning B: Urban analytics and City Science, 25(3), 345-365.

Srinivasan, K., Pradhan, G., \& Naidu, G. (2007). Commute mode choice in a developing country role of subjective factors and variations in responsiveness across captive, semicaptive, and choice segments. Transportation Research Record, 2038, 53-61.

St-Louis, E., Manaugh, K., van Lierop, D., \& El-Geneidy, A. (2014). The happy commuter: A comparison of commuter satisfaction across modes. Transportation Research Part F, 26, 160-170.

Tongii University. (2011). Residents travel demand analysis and transportation planning strategy in largescale residential areas on the periphery of Shanghai central city. Shanghai: School of Transportation Engineering.

Vehicle license's price tendency in Shanghai (2015). Retrieved from 51chepai.com.cn/paizhaojiage

Walker, J. (2001). Extended discrete choice models: Integrated framework, flexible error structures, and latent variables (Doctoral dissertation). Massachusetts Institute of Technology, Boston.

Yang, J. (2006). Transportation implications of land development in a transitional economy: Evidence from housing relocation in Beijing. Transportation Research Record, 1954, 7-14.

Yang, W., Chen, Y., Cao, X., Li., T., \& Li, P. (2017). The spatial characteristics and influencing factors of modal accessibility gaps: A case study for Guangzhou, China. Journal of Transport Geography, 60, 21-32.

Ye, R., \& Titheridge, H. (2017). Satisfaction with the commute: The role of travel mode choice, built environment and attitudes. Transportation Research Part D, 52B, 535-547.

Zhang, M., Shen, Q. \& Sussman, J. (1999). Strategies to improve job accessibility: Case study of Tren Urbano in San Juan metropolitan region. Transportation Research Record, 1669(1), 53-60.

Zhao, P. (2011). Car use, commuting and urban form in a rapidly growing city: Evidence from Beijing, Transportation Planning and Technology, 34, 509-527.

Zhao, P., Lu, B., \& de Roo G. (2011). The impact of urban growth on commuting patterns in a restructuring city: Evidence from Beijing. Regional Science, 90(4), 735-754.

Zhao, J, Webb, V., \& Shah, P. (2014). Customer loyalty differences between captive and choice transit riders, Transportation Research Record, 2415, 80-88.

Zhou, Y. (1997). On the Suburbanization of Beijing. Chinese Geographical Science, 7, 208-219. 